\title{
THE PERKS AND DOWNSIDES OF TEACHING ENGLISH ONLINE
}

\section{Cristina-Laura ABRUDAN, loana-Claudia HOREA}

Faculty of Economic Sciences, University of Oradea, Oradea, Romania

cabrudan2003@yhaoo.com

ihorea@gmail.com

\begin{abstract}
In the 1990s, the rise of the Internet throughout the world helped significantly the job of the English language teachers, in ways of having access to vast information and access to new methods of teaching foreign languages. We think that, back then, nobody thought of what technology and access to Internet would mean to us one day. But since the beginning of 2020, the world has been going through an unprecedented crisis. The pandemic has changed everything: family behaviour, schools, businesses, environment, and so on and so forth. The world has been divided into two: the businesses and companies that have been stopped and the sector of the jobs that continued working. Since many countries have faced lockdowns, subsequently many schools have closed their doors. The teachers have faced the situation of delivering courses using virtual classrooms, not matter how tech-shy they have been. Of course, online teaching English has both advantages and disadvantages. The question is simple: do the perks outweigh the downsides of teaching English online? The answer is difficult. It depends on every teacher. The present paper is trying to throw some light on this question.
\end{abstract}

Keywords: teaching English; innovation; on-line technologies; education research.

JEL Classification: J60

'The next big killer on the Internet will be education. Online education will be so great that it will make email use seem like a rough mistake.' Cisco Systems CEO, John T. Chambers stated in 1999. And so, it happened.

\section{Introduction}

In March 2020, our lives began to look different. Even though, none of us understood what was going on, we still had to face the reality of a lockdown regarding all aspects of our lives. Consequently, the lockdown movement had a great impact on schools, on our teaching methods and on our way of using technology. Thus, for teachers, using virtual classrooms and providing online selfstudy materials for students have become the new way of delivering the act of education. The 'new normal' in education has triggered new ways of learning. Today, digital learning has emerged as a necessary resource for students and schools all over the world, whether we like it or not; and for certain types of learners, there are incredible benefits. Still, many teachers nowadays are reluctant to teaching online since it lacks face-to face contact with the students, it can be focused more on grading than on teaching, and the technological expertise for undergoing this task is often limited, lacking pedagogical skills. Critical thinking, problem-solving and communication represent some of the key factors that 
influence learning. If the students are successful in controlling these factors, the success of distance learning is fulfilled. As with most teaching methods, online learning also has its own set of perks and downsides. Decoding and understanding these positives and negatives will help teachers create strategies for being more efficient in the act of delivering the lessons, thus ensuring an uninterrupted learning journey for students. This is the topic of the present paper, having the aim to highlight the advantages and disadvantages of online learning.

\subsection{The concept and definition of E-learning}

Since the great appearance of the Internet that has radically changed our lives, the international network has gained the recognition of one of the vital ways of making resources and information available, both for research and learning, for teachers and students, in order to acquire and share information. Online learning, also known as e-learning, is actually the acquisition of knowledge which takes place virtually, by means of media and electronic technologies, encompassing the use of the Internet in order to produce materials for learning, covering a large range of applications, learning methods and processes. There has been large debate on the topic of a common definition for the term online learning, or e-learning and researchers don't seem to have found a common point. Thus, it is difficult to find a definition that has been commonly accepted. According to Rossi (2009), Hawkins (2008) and Dublin (2003), there is no common definition for the term. Hawkins (2008) noted that 'e-Learning has transformed from a fully-online course to using technology to deliver part or all of a course independent of permanent time and place'. Also, in 2001, the European Commission describes e-learning as 'the use of new multimedia technologies and the Internet to increase learning quality by easing access to facilities and services as well as distant exchanges and collaboration'. Abbad et al (2009) regard as e-learning, any type of learning activity that is undergone by means of electronic equipment, thus, narrowing somehow the definition of online learning to learning that is empowered by the use of the Internet, actually by the use of digital technologies. According to OECD (2005) elearning is defined as 'the use of information and communication technologies in diverse processes of education to support and enhance learning in institutions of higher education and includes the usage of information and communication technology as a complement to traditional classrooms, online learning or mixing the two modes. ' Another point of view is expressed by Wentling et al in 2000 , when the term e-learning is used to express the attainment and use of knowledge that are mainly distributed and facilitated by electronic means. In some definitions, elearning refers to using the computer and the communication technologies that enable the access to the internet while in some others, the term e-learning refers to the attainment and use of knowledge that are mainly distributed and facilitated by electronic devices. Some other researchers consider that e-learning is a revolutionary approach of studying which enables the students the access to an interactive system, that is customizable, repetitious, and self-paced.

But all these definitions have certain common points that must be mentioned: elearning summarizes a revolutionary approach centred on the learner that can customize his/her process of learning, giving the students the possibility of individualized support; it proposes a multimedia environment that gives freedom to 
its students; the multimedia constructs have changed the process of learning into a more active and enjoyable one. Thus, the practices of e-learning require a deep evaluation before being implemented in the process of learning. The consideration of gains and losses of using particular education technologies, methodologies represent an important part of this evaluation.

\subsection{The history of E-learning}

Francis Bacon, a British philosopher, stated in the 1600s that Knowledge is power. Thus, the one who has knowledge has also power in all the domains of our lives: power over nature, power over people, power over thoughts, power over everything that surrounds us. Moreover, knowledge is given by education, whether it is elearning or traditional, education has a vital role in the world today.

The first official recognition of education through correspondence took place in 1883, the University of Wisconsin and the University of Chicago establishing major correspondence programs. In the 1960s and 1970s, due to the development of new media technologies, significant changes occurred in long distance learning. The success of satellite communication, in 1965, brought about an increased level of experimentation with educational programs via satellites. The tools that were at hand, such as television, telephone, and videotapes gave free way to the more complicated and sophisticated educational programs. This is the way in which, in the 1990s, long distance education was developing at an unprecedented pace. The Internet and the digital applications added a whole new dimension to the term of distance learner, bringing along educational opportunities to the nontraditionnal learner. Along with the appearance of these, the term e-learning started to take shape. According to Laurillard (2004) 'e-learning describes the interaction in which students use different types of ICTs in their learning process.' Both for the students and for the teachers, the ICTs and e-learning are extremely important. They create more flexible solutions for both parties involved in the educational process. In 2009 , the courses which were held online reached $65 \%$. The number has been steadily increasing ever since.

\subsection{Types of E-learning}

According to Aparicio, Bacao \& Oliveira 'The e-learning systems' theoretical framework contains the three main components of information systems. These components are people, technologies, and services. People interact with e-learning systems. E-learning technologies enable the direct or indirect interaction of the different groups of users. Technologies provide support to integrate content, enable communication, and provide collaboration tools. E-learning services integrate all the activities corresponding to pedagogical models and to instructional strategies. The complex interaction combination is the direct or indirect action with e-learning systems. At the same time, systems provide services according to the specified strategies for activities. In other words, service specifications are elearning activities aligned with the e-learning pedagogical models and the instructional strategies'.

There are several ways of classifying the e-learning types, according to: the learning tools, the extent of the engagement in education and the timing of the 
interaction. Scientist have identified the following categories: computer assisted instruction (CAI), computer assisted learning (CAL), computer-based education (CBE), learning management systems (LMS), and massive open online courses (MOOC). The two common aspects of these concepts are: learning and computers. In the case of computer-based learning, there is a full range of hardware and software that comprises it and each component can be used in either of two ways: computer managed instruction and computer assisted learning. In the first category, the computer replaces the traditional methods, providing the interactive software as a support tool during the classes. It operates with through information databases. However, the computers have the role of storing and retrieving information, helping in the management of education, containing the information that the student has to learn. On the other hand, the internet-based learning represents a step forward in the computer assisted learning, having links and knowledge sources that can be used by learners at any time and in any place. Interactivity is the primary value of this type of learning, allowing students to become interactive learners not just passive ones.

Some other scientists make a difference between synchronous online learning and asynchronous online learning. When talking about learning, synchronous learning refers to an event in which all the participants are engaged in the process of learning at the same time. There are several advantages of this type of learning, among which we mention: the participants can interact, the teacher can give realtime feedback to the students, the schedule is fixed, and the participants can share their knowledge and experience. On the other hand, asynchronous learning refers exactly to the opposite. There is no real-time interaction between the participants, the teacher isn't engaged in the process at the same time with the students, and there isn't a fixed schedule. Of course, this type of e-learning has its own advantages too: the participants can learn according to their own schedule, automated tasks reduce the repetitive work, the work of the teacher is somehow reduced as the pre-recorded videos, audio files, and webinar recordings can be used several times. Among other types of e-learning we mention fixed e-learning, adaptive e-learning, linear e-learning, interactive e-learning, individual online learning and collaborative online learning. Fixed e-learning refers to the fact that the material used does not change from its original variant and all the students receive the information in the same way, without any changes from group one grout to another, being predetermined and without being adapted to the students; preferences. On the other hand, the adaptive e-learning is a relatively new and adaptive type of e-learning which can be adapted and redesigned for each group of students, allowing the process of learning to be more student-centred and more individualized. The interactive e-learning permits the two parties implied in the process to switch roles thus the sender becomes the receiver and vice-versa. But what does this actually mean? It means that, from the messages that have been sent and received the students can change their learning methods and the teachers can change their teaching methods. The Internet has an enormous potential for rapid dissemination of information and knowledge and these are just a few examples of e-learning types.

Elliott Masie, a New-York-based training think tank's president estimated that $92 \%$ of large organisations worldwide will use one form or another of online learning. 
The designing, the developing and the delivering online teaching has several distinct advantages and disadvantages.

\section{Advantages and disadvantages}

The traditional way of teaching/learning has encountered a wide range of issues, beginning with the management of the classes, scheduling, assessing, ending with communicating and balancing the face-to-face classes. In view of these issues, the concept of online teaching has started to be more and more present in the field of English Language Teaching. On the other hand, the online mode of teaching/learning has endowed a new set of advantages and disadvantages, as there is no perfect way of teaching/learning.

\subsection{Advantages}

\section{1) EFFICIENCY}

Online teaching offers a number of tools such as videos, PDFs, podcasts, and teachers can use these tools as part of their lessons. By extending the lesson plan beyond the traditional textbooks, teachers are able to become more efficient educators since the young generation's life, as a whole, depends on gadgets.

\section{2)SUITABILITY, EXTENDIBILITY AND ACCESIBILITY}

The most obvious advantage of online learning is that it allows people to learn in their own way, at their own pace, absorbing as much information as they can. The fact that students can attend classes from any location of their choice is another advantage, allowing universities to reach out to a more extensive network of students without being restricted by geographical boundaries. Moreover, if some students need more time on a certain topic, they can go through it over and over again, as slowly as they can and as many times as they wish. Also, the fact that they can listen to the material or read the original material can facilitate knowledge retention.

\section{3) REDUCED COSTS}

This is one of the most obvious advantages of online learning since researchers have stated that half-day of traditional training is equivalent to a one-hour elearning course. The reduced financial cost transforms online education in a more affordable one as compared to physical learning since there are no more accommodation costs, transportation costs, meals for students, and so on and so forth. Expenses regarding students' travel, training facilities, in-house training development and equipment do not represent an issue anymore.

\section{4) COLLABORATIVE AND EXPLORATORY LEARNING ENVIRONMENTS}

The entire process of learning is based on exploration, as students explore the content of a course, on their own, building a solid knowledge base, cooperating and collaborating in order to uncover information, share the findings and solve exercises and problems together. The online teaching/learning system allows the learners to approach problems in different ways, according to relevance, adopted strategies and learning mechanisms.

\section{5) EASE OF CONTENT UPDATE}

In today's world, information and knowledge change faster than ever. With printed materials, the whole process of sharing information for teachers is a complex one, being also costly and sometimes time-demanding. On the other hand, on-line courses can be adapted easily and the changes undergone by the teacher can 
instantaneously be available to the students. Moreover, the fact that students can have access to the changes of the course on the spot, as their teacher is undergoing them, is definitely an advantage, being a friendly way to transmit the information adapted to the needs of the students.

\section{6) CONTROLLED ACCES AND IMPROVED STUDENT'S ATTENDANCE}

From the teacher's point of view, one of the main advantages of online teaching is that you can direct and monitor exactly who receives the training. Moreover, you the teacher can collect a lot of information regarding the students' activity: when the students access the discipline's page, how many times, how they organise their work and also you have full access to their work, including homework, projects, and so on and so forth. On the other hand, since online classes can be taken from home or location of choice, there are fewer chances of students missing out on lessons.

\subsection{Disadvantages}

Besides the advantages mentioned in the lines above, the teaching/learning activity encounters a lot of disadvantages too, which can be seen as challenges that both teachers and students must overcome. In this respect, we will try to give also some hints how to overcome these challenges.

\section{1) Difficulty in adaptability}

Both the students and the teachers who have always been studying in the traditional way find it difficult to adapt to the online environment, to focus on the online platform at once, and also to meet today's educational demand. The era of globalisation has brought about the era of information economy and the era of technology and therefore teachers must continuously update their knowledge and skills. The slower the adaptability process is, the slower the results of the teaching/ learning results appear. And we all know that the quality of the human capital comes from a quality education process.

\section{2) Online learning/teaching requires self-discipline}

The fact that online learning creates a sense of isolation is known to everyone. Students physically attending classes increases accountability and the sense of proper guidance. If these lack and the students have the feeling of not being part of a community, they may not have enough self-discipline and they may not have enough discipline to fully engage in the lessons themselves. In order to keep the students engaged, teachers have to use tools like real-time classes instead of just online classes, live quizzes, giving the students a greater sense of accountability. The current generation of students may be more satisfied with the online methods but the teachers must bring to their attention that self-discipline is crucial in achieving results.

\section{3) Additional training for teachers}

In order to create successful online classes, teachers must make extra effort to increase their knowledge, continuously developing their expertness to implement innovative way of teaching strategies. The results of the courses depend mostly on the positive learning relationships between the students and the teachers and also 
on the effective learning environment that can be created through online method of handling English language teaching. Online classes have a lot of advantages. Thus, the teachers need to have a deeper understanding of the different approaches to teaching and learning, making the most of the tools that online teaching has to offer. This is, of course, a time-demanding activity and for the ones who are more accustomed to the traditional way of teaching/learning, this could represent a disadvantage. On the other hand, teachers need proper training regarding the use of the technical equipment, otherwise they do not know how to offer the most of the benefits that technology offers us. For the teachers, proper training means new skills that represent a steep learning curve, but thoughtful investment in proper training will pay off both for the institution, where teachers work, and for the teachers.

\section{4) Technical issues}

Everybody knows that technology is complex and its complexity makes online classes be prone to technical issues. Connection issues that disrupt online classes are extremely unpleasant both for the teacher and for the students. In the past, students were required to install cumbersome apps that would deliver information that sometimes was inconsistent. Nowadays, things have changed, and we are as far as a click from online classes, without having the need of installing anything. Not only the Internet worldwide has increased dramatically but also the students' devices have improved significantly.

\section{5) More screen-time}

The raise of the Internet, the appearance of the technology, the digitalisation throughout the world have all led to a frightening amount of time spent by everyone in front of screens. Sadly, online classes contribute a great deal to this problem. Excessive screen-time can lead to all sorts of problems, including health problems like headaches and poor posture but also psychological problems that can root from the sense of isolation that we all have during this process. Students can also have problems regarding focusing, since the Internet can distract us with social media and entertainment that is just a click away. Good online platforms and software have all kinds of features and tools that can help students stay engaged in the complex process of learning.

\section{Conclusions}

In the present paper we have tried to put forward the idea that along with the idea of globalisation, the Internet and the development of technology, the spread of online teaching/learning have posed new challenges to teachers in general, not only to language teachers. The recent boom in the development of the mobile technologies and of the Internet has given way to the present-day students and teachers to an unrestricted access to information, knowledge and learning, which led to the re-conceptualization of the meaning of communication and the purpose of our teaching. New learning and education patterns have emerged due to the rapid transfer in the field of technology. In order to meet today's educational demands today's teacher needs to focus on 'professional development'. As Hargreaves and Fullan say 'the teacher is the ultimate key to educational change 
and school improvement'. Especially language teachers can use their own practice for developing attractive and challenging strategies in the online mode by exploring the opportunity to easily share information and collaborating on a wide range of topics and projects. Of course, there are advantages and disadvantages since no learning/teaching method is flawless. Generally speaking, it is always advisable to take into consideration the fact that online learning/teaching can be accessed from anywhere and anytime, being cost-effective providing consistent and standardized training every time. The experience is the same for all the students, each having unique preferences and goal. Online learning has the possibility of catering to individual needs, giving us the possibility of having another look at what we have been doing in our classrooms in terms of methods, strategies and outcomes. As we have stated in the lines above, online teaching and learning have a wide range of advantages, posing some challenges, too. The role of the teachers is to monitor the engagement of the students in classes, to teach, to provide advice for students and also to help in coping with the abrupt crises that can often occur, therefor being crucial to understand both the perception of the teachers and of the students concerning online classes.

\section{References}

1.Abbad, M. M., Morris, D., \& de Nahlik, C., Looking under the Bonnet: Factors Affecting Student Adoption of E-Learning Systems in Jordan. The International Review of Research in Open and Distance Learning, 2009

2. Casey M., Shaw E., Online Teaching, Rowman\&Littlefield Press, 2017

3. Ellis, A., Goodyear, P., Students' Experience of E-learning in Higher Education. New York: Routledge, 2009

4. Fee, K., Delivering E-learning: A Complete Strategy for Design, Application and Assessment. London: Kogan Page, 2009

5. Hargreaves A., Fullan M, The Power of Professional Capital, http://www.michaelfullan.ca/wp-content/uploads/2013/08/JSD-Power-of-

Professional-Capital.pdf

6. Hargreaves A., Fullan M, Professional Capital: Transforming Teaching in Every School, Teachers College Press, 2019

7.https://www.fastcompany.com/1093654/how-ciscos-ceo-john-chambers-turningtech-giant-socialist

8. Jfenthaler D., Sampson D., Online Teaching and Learning in Higher Education, Springer International Publishing, 2020

9. Major C., Teaching Online, Johm Hopkins University Press, 2019

10. Meskill C., Online Teaching and Learning, Bloomsbury Publishing House, 2019

11. Murphy D., Online Learning and Teaching with Technology, Taylor\&Francis Ltd. Publishing Hourse, 2018

12. OECD, E-learning in tertiary education [Online]. Available at http://www.cumex.org. (Accessed 27 /02/ 2014), 2005 